\title{
INFLUENCE OF THE CUSTOMER EXPERIENCE ON SATISFACTION WITH MOBILE PHONES
}

\author{
Marina DOBROTA ${ }^{1}$, Ana NIKODIJEVIĆ ${ }^{2}$, Dobrivoje MIHAILOVIĆ ${ }^{2}$ \\ ${ }^{1}$ University of Belgrade, Faculty of Organizational Sciences, 11000 Belgrade, Jove Ilića 154, Republic of Serbia. \\ E-mail: dobrota.marina@fon.bg.ac.rs \\ ${ }^{2}$ University of Belgrade, Faculty of Organizational Sciences, 11000 Belgrade, Jove Ilića 154, Republic of Serbia.
}

Accepted 1 November, 2012

\begin{abstract}
Global usage of mobile phones initiated a large number of researchers to devote their attention to researching the field of customer satisfaction and implementing postulates of customer behavior in the industry. As there are not many relevant studies conducted in Serbia, in this study we examine the influence of the customer experience on satisfaction with mobile phones. Online survey was used as a method of collecting data from 340 randomly chosen respondents. The findings confirm that experience is in a fact a significant determinant of satisfaction and that there are differences according to types of mobile phones customers use and the frequency of usage. Furthermore, high levels of satisfaction are seen in customers familiar with current models of mobile phones and those following mobile trends.
\end{abstract}

Key words: customer satisfaction, customer experience, mobile phones

\section{INTRODUCTION}

Since the launch of mobile phones, there has been a remarkable development both in their product sophistication and their fast and global adoption (Bayraktar et al., 2012). Nowadays, customers are continuously facing the dilemma: which phone to buy. After the smart phones have been released, the choice seemed to be even harder, since the opportunities and offers that producers are providing are endless (Seongwon et al., 2011; Milutinovic et al., 2011).

Over the past decade, the mobile phone industry has increasingly recognized the meaning of customer satisfaction and experience. In rapidly changing business environment today, customer satisfaction is a critical factor for mobile phone industry to maintain and improve their profitability. Prior studies have found that customer satisfaction contributes to company's profitability and customer loyalty (Fornell, 1992; Fornell et al., 1996) and several authors claim that higher customer satisfaction can lead to higher market share (Fornell, 1992). Consumer satisfaction is central to customer behavior concept and it is now common to find customer satisfaction as one of important goals in company politics (Fournier and Mick, 1999).
Customer satisfaction is generally assumed to be a significant determinant of repeat sales, positive word-of-mouth, and customer loyalty. Satisfied customers return and buy more, and they tell other people about their experiences, both positive and negative (Fornell et al., 1996). Many other researchers have recognized the need for investigating the customers' satisfaction, experience, and loyalty in the past (Deng et al., 2010; Verkasalo, 2010; Lee, 2011; Bong-Won and Kun Chang, 2011; Lee et al., 2011).

Customers engage in a constant process of evaluating the things they buy as they integrate these products into their daily activities (Fournier and Mick, 1999). Oliver (1981) defined customer satisfaction as "the summary psychological state resulting when the emotion surrounding disconfirmed expectations is coupled with the consumer's prior feelings about the consumption experience". Customer satisfaction or dissatisfaction is determined by the overall feelings, or attitude, a person has about a product after it has been purchased (Solomon, 2004).

The concept of customer satisfaction is a function of customer expectations (Schiffman and Kanuk, 2004). A customer whose experience falls below 
expectations (e.g. mobile application does not work fast enough) will be dissatisfied. Customers whose experiences match expectations will be satisfied. And customers whose expectations are exceeded will be very satisfied or delighted. Therefore, we can define customer satisfaction as the individual's perception of the performance of the product or service in relation to his or her expectations. Customers will have drastically different expectations of a new expensive mobile phone and a five year old model.

Creating satisfied customers, and thus future sales, requires that customers continue to believe that the brand meets their needs and offer superior value when they use it. Companies must deliver as much value as customers initially expected, and it must be enough to satisfy their needs (Hawkins et al., 2004). It is generally more profitable to maintain existing customers than to replace them with new ones. Retaining current customers requires that they be satisfied with their purchase and use of the product.

Next section states the hypotheses considered in this research, thus forming the conceptual framework of the conducted research. The survey is explained in detail in Section 3, focusing on the research sample, instruments, and methodology. Fourth section presents the results of the research. Finally, the concluding remarks are given.

\section{RESEARCH HYPOTHESES}

The focus of this paper is on evaluating the customer satisfaction by analyzing the influence of previous customer experiences while using different mobile phone brands in Serbian mobile phone sector. The general hypothesis of this research is:

H1: Customer experience influences their satisfaction with mobile phones.

From the general hypothesis, and according to a research subject, we extracted two specific hypotheses:

H1.1: There is a difference in customer satisfaction with mobile phones according to the characteristics of mobile phones.

H1.2: There is a difference in customer satisfaction with mobile phones, according to the customer experience.

In order to clearly define the research and separate these hypotheses into component parts, we defined four individual hypotheses:

H1.1.1: The difference in customer satisfaction with mobile phones, according to different types of mobile phones they use, is statistically significant.

H1.2.1: The difference in customer satisfaction with mobile phones, according to how frequently they use their phones, is statistically significant.

H1.2.2: The difference in customer satisfaction with mobile phones, according to their familiarity with current models of mobile phones, is statistically significant.

H1.2.3: The difference in customer satisfaction with mobile phones, according to how often they follow mobile trends, is statistically significant.

\section{SAMPLING AND METHODOLOGY}

The study was conducted in Serbia, using the online survey. The survey was anonymous. It was conducted using random sampling methodology. Collected sample consisted of 340 respondents.

\section{Instruments}

The questions used in the survey were grouped in four parts. The first part addressed demographic data, including data on age, sex, education level, average mark on studies and the employment. The second part of the questionnaire was related to the mobile phone usage frequency and foreknowledge. It included questions on how often do customers follow trends related to the mobile phones and mobile OS, are they familiar with current models of mobile phones, which mobile phone do they use, for which purpose do they mostly use their mobile phones, do they use multitasking and how frequently do they use mobile phone.

The third part of the questionnaire was related to customers' opinion on quality characteristics of mobile OS. Following characteristics were examined:
- Functionality
- $\quad$ Speed
- $\quad$ Use simplicity
- $\quad$ Price and quality ratio
- Multitasking
- Availability and possibility of installing new applications
- $\quad$ Amount of bugs
- $\quad$ Internet surfing simplicity

Similarly, the fourth part was related to customers' opinion on quality characteristics of mobile phones:

$-\quad$ Shape and form
$-\quad$ Keypad


- Screen size and resolution

- Camera resolution and image quality

- Quality of conversation

- Quality of sound

- $\quad$ Additional equipment

Customers' satisfaction with mobile phones was measured using a variable created in this research: Phone Satisfaction. This variable measures customers' satisfaction with mobile phones, consisting of the questions from the fourth part of the questionnaire.

To create this variable, we used 5-point Likert scale. It consisted of seven items in a construct. A Cronbach's alpha coefficient for internal consistency of the scale was 0.865 , pointing out on a good internal consistency (Cronbach, 1951; George and Mallery, 2003).

\section{Sample}

Respondents were mostly aged from 20 to 25 (65\%), and 25 to 30 (24\%). Regarding the education, $48 \%$ were graduates, while $24 \%$ have finished high school, $17 \%$ were bachelors and $11 \%$ have finished postgraduate studies. The percentage of males was 41, and females 59. Respondents were mostly employed (59\%), while $13 \%$ were unemployed, and there were $26 \%$ of students. There were $10 \%$ of customers, who use a phone for business purpose, while $46 \%$ use it for private and $44 \%$ for both private and business purpose. Information on customers' foreknowledge and experience with mobile OS and phones, collected in the survey, is presented in Table 1.

Table 1: Customer experience on mobile phones

\begin{tabular}{|l|c|c|c|}
\hline \multicolumn{1}{|c|}{ Groups } & \multicolumn{3}{c|}{ Customers' experience (\%) } \\
\hline How often do customers follow trends related to the & Rarely & Medium & Often \\
\cline { 2 - 4 } mobile phones? & 27 & 21 & 52 \\
\hline $\begin{array}{l}\text { Are customers familiar with current models of } \\
\text { mobile phones? }\end{array}$ & Not at all & Partly & Completely \\
\cline { 2 - 4 } & 7 & 68 & 25 \\
\hline \multirow{2}{*}{ How frequently do customers use mobile phones? } & Rarely & Medium & Very often \\
\cline { 2 - 4 } & 5 & 21 & 74 \\
\hline
\end{tabular}

\section{Methods}

In order to establish the accuracy of our assumptions appropriate parametric tests were performed. We used parametric independent samples t-test in order to establish the difference between two groups, and accordingly the ANOVA test (Lilliefors, 1967), to establish the difference among three or more observed independent groups. To track statistically significant differences, we used Tukey multiple comparisons test. The means where calculated in order to locate the differences (among which groups do the differences occur).

\section{RESULTS AND DISCUSSION}

Central part of the research is related to the Phone Satisfaction, which is directly associated with our initial assumptions. Table 2 presents the results of confirmatory data analysis. Leven's Homogeneity of variance test had confirmed that the assumption on homogeneity of variances among the groups was not disturbed in any of the assumptions. We used parametric ANOVA test to establish whether there was a statistically significant difference among specified groups.

H1.1.1: The first hypothesis presumes that difference in customer satisfaction with mobile phones, according to different types of mobile phones they use, is statistically significant. Customers were divided into the groups according to their mobile phone type. The results of parametric ANOVA test showed that the difference in satisfaction among the specified groups is statistically significant at 0.05 significance level. The value of $\mathrm{F}$ statistics was $2.680, \mathrm{p}=0.022$, which proves that these groups are not equally satisfied with mobile phones. Influence of the difference expressed by $\eta^{2}$ (eta-squared) indicator is 0.038 , which indicates that the influence is medium (Cohen, 1988). From the Figure 1 it is evident that customers are most satisfied with iPhones, followed by HTC and others, while they are less satisfied by Sony Ericsson, Nokia and Samsung.

H1.2.1: Our next assumption was that the difference in customer satisfaction with mobile phones, 
according to the frequency of phone usage, is statistically significant. The groups of customers according to this criterion are customers that use phone: rarely, medium, and very often (Table 1). The results of ANOVA test show that there is a statistically significant difference in satisfaction among these groups at 0.01 significance level. The value of $\mathrm{F}$ statistics was $10.826, \mathrm{p}<0.001$, proving that these groups are not equally satisfied with mobile OS. The $\eta^{2}$ (eta-squared) indicator is 0.06 , reporting on the medium influence (Cohen, 1988). The results of Tukey HSD test, showed that the differences occur among the group that uses phone very often $(\mathrm{M}=26.897, \mathrm{SD}=4.9)$, and two other groups (rarely: $\mathrm{M}=22.182, \mathrm{SD}=5.4 ;$ medium: $\mathrm{M}=24.437, \mathrm{SD}=5.58$ ). Other two groups (rarely and medium) do not differ from each other with statistical significance. Differences are shown in Figure 2.

Table 2: The results of the ANOVA data analysis

\begin{tabular}{|l|c|c|}
\hline \multicolumn{1}{|c|}{ Hypothesis } & Test value & Acceptance \\
\hline $\begin{array}{l}\text { H1.1.1: The difference in customer satisfaction with mobile } \\
\text { phones, according to different types of mobile phones they } \\
\text { use, is statistically significant. }\end{array}$ & $2.680^{*}$ & Accepted \\
\hline $\begin{array}{l}\text { H1.2.1: The difference in customer satisfaction with mobile } \\
\text { phones, according to the frequency of phone usage, is } \\
\text { statistically significant. }\end{array}$ & $10.826^{* *}$ & Accepted \\
\hline $\begin{array}{l}\text { H1.2.2: The difference in customer satisfaction with mobile } \\
\text { phones, according to their familiarity with current models of } \\
\text { mobile phones, is statistically significant. }\end{array}$ & $15.248^{* *}$ & Accepted \\
\hline $\begin{array}{l}\text { H1.2.3: The difference in customer satisfaction with mobile } \\
\text { phones, according to how often they follow mobile trends, is } \\
\text { statistically significant. }\end{array}$ & $28.133^{* *}$ & Accepted \\
\hline
\end{tabular}

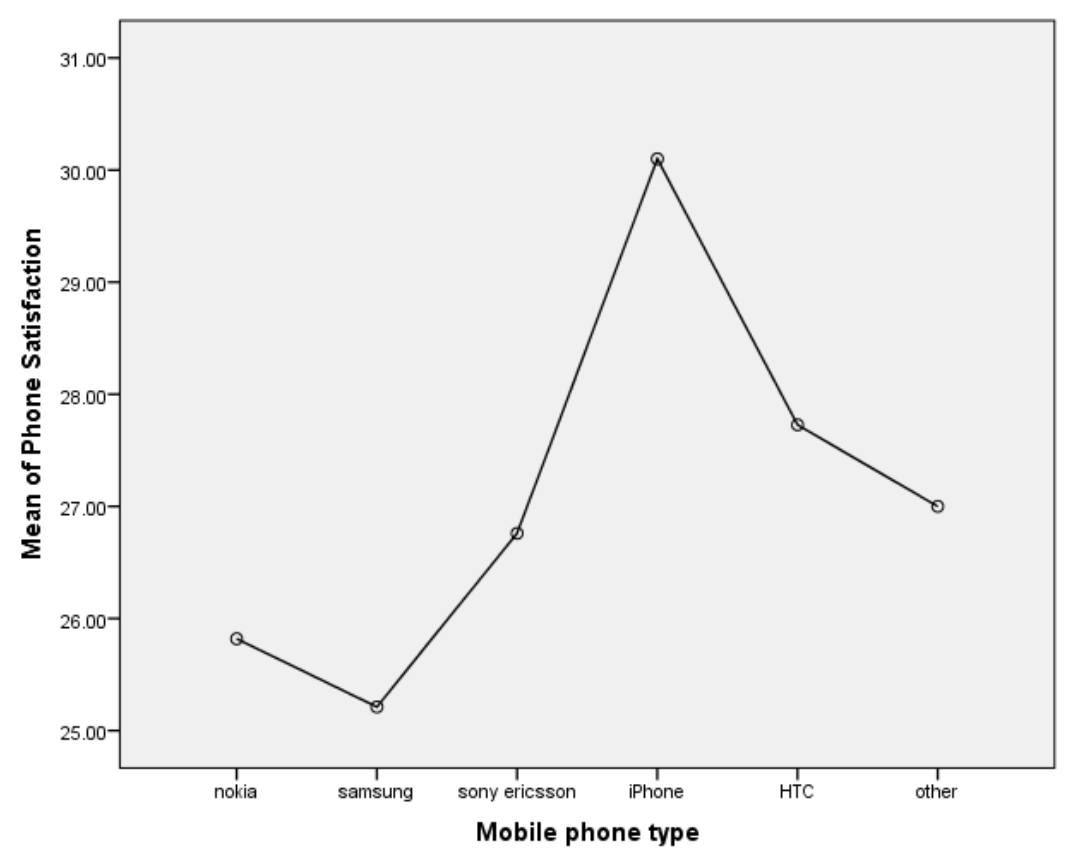

Figure 1: Differences in customer satisfaction among users according to mobile phone type

H1.2.2: This hypothesis says that the difference in customer satisfaction with mobile phones, according to their familiarity with current models of mobile phones, is statistically significant. There were also three groups of customers according to their answered the question about their familiarity with current models of mobile phones: not at all, partly, and completely (Table 1). 


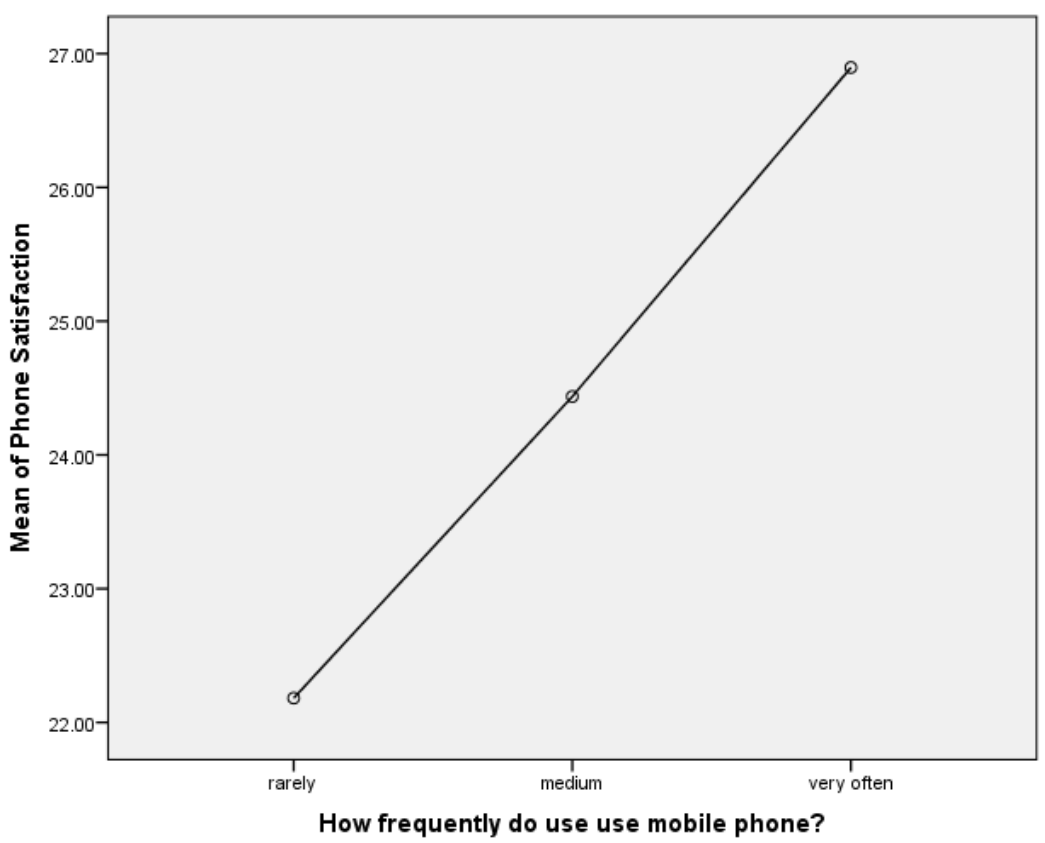

Figure 2: Differences in customer satisfaction among users according to mobile phone usage frequency

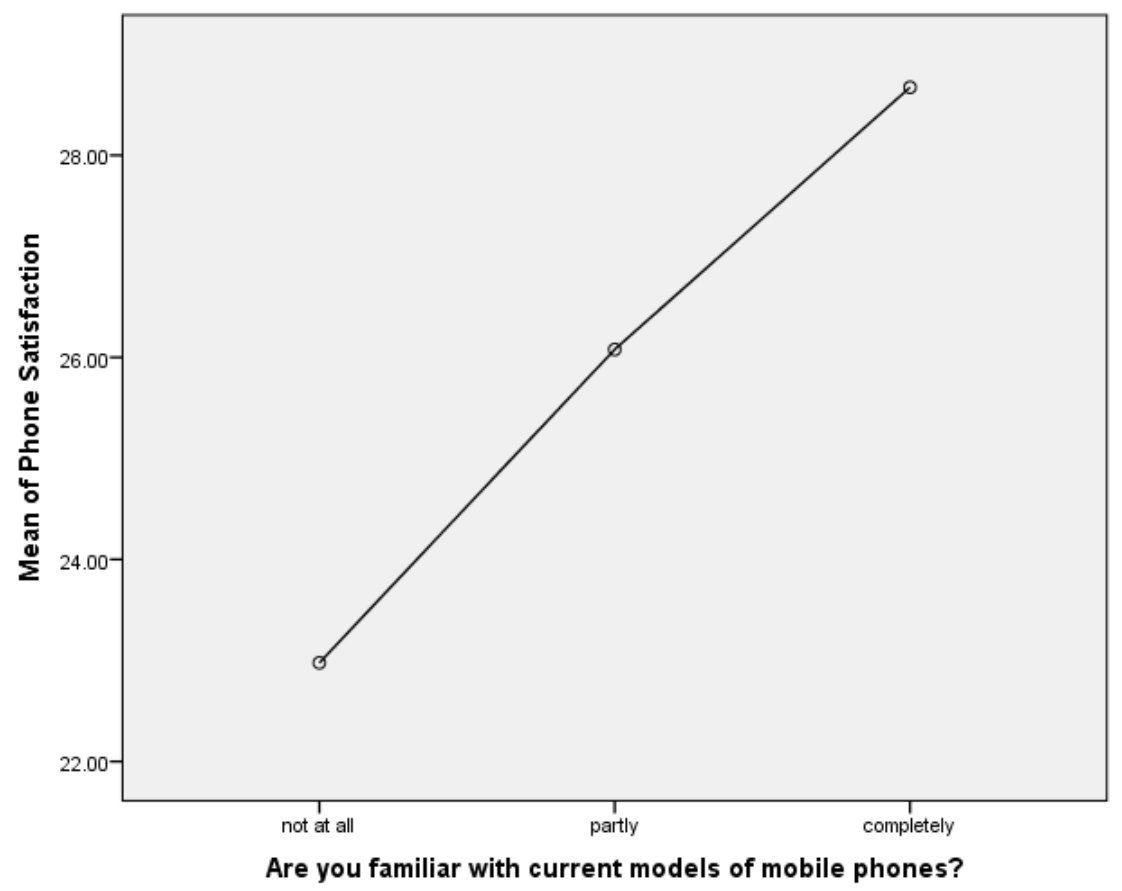

Figure 3: Differences in customer satisfaction among users according to familiarity with current models

The results of parametric ANOVA test showed that the difference in satisfaction among the specified groups is statistically significant at 0.01 significance level. The value of F statistics was 15.248, $p<0.001$, which proves that these groups are not equally satisfied with mobile phones. Influence of the difference expressed by $\eta^{2}$ (eta-squared) indicator is 0.083 , which indicates that the influence is medium (Cohen, 1988). The subsequent analysis with Tukey HSD test, showed that these differences occur among all three groups (not at all: $\mathrm{M}=22.976$,
$\mathrm{SD}=5.795$; partly: $\mathrm{M}=26.078, \mathrm{SD}=5.05$; completely: $\mathrm{M}=28.673, \quad \mathrm{SD}=4.312$ ). The differences are presented in Figure 3 and we can see that customers, who are not familiar with current models of mobile phones, are less satisfied with it than other groups. Customers that are partly familiar are more satisfied and customers that are completely familiar with current state of the market are most satisfied with their choice of mobile phone. 
H1.2.3: Finally, we assumed that the difference in customer satisfaction with mobile phones, according to how often they follow mobile trends, is statistically significant. Customers were divided in three groups, according to the answer to the question on how often they follow new trends: rarely, medium, and often (Table 1). The results of parametric ANOVA test showed that the difference in satisfaction among the specified groups is statistically significant at 0.01 significance level. The value of $\mathrm{F}$ statistics was 28.133, $\mathrm{p}<0.001$. Influence of the difference expressed by $\eta^{2}$ (eta- squared) indicator is 0.143 , which indicates that the influence is large (Cohen, 1988). Tukey HSD test, showed that these differences occur among all three groups (rarely: $\mathrm{M}=23.337, \mathrm{SD}=5.11 ;$ medium: $\mathrm{M}=26.366, \mathrm{SD}=4.678$; often: $\mathrm{M}=29.014, \mathrm{SD}=4.13$ ). It is evident, from Figure 4, that customers, who often follow trends related to the mobile phones, are most satisfied with it, followed by customers that medially follow trends related to the mobile phones and customers that rarely follow trends related to the mobile phones.

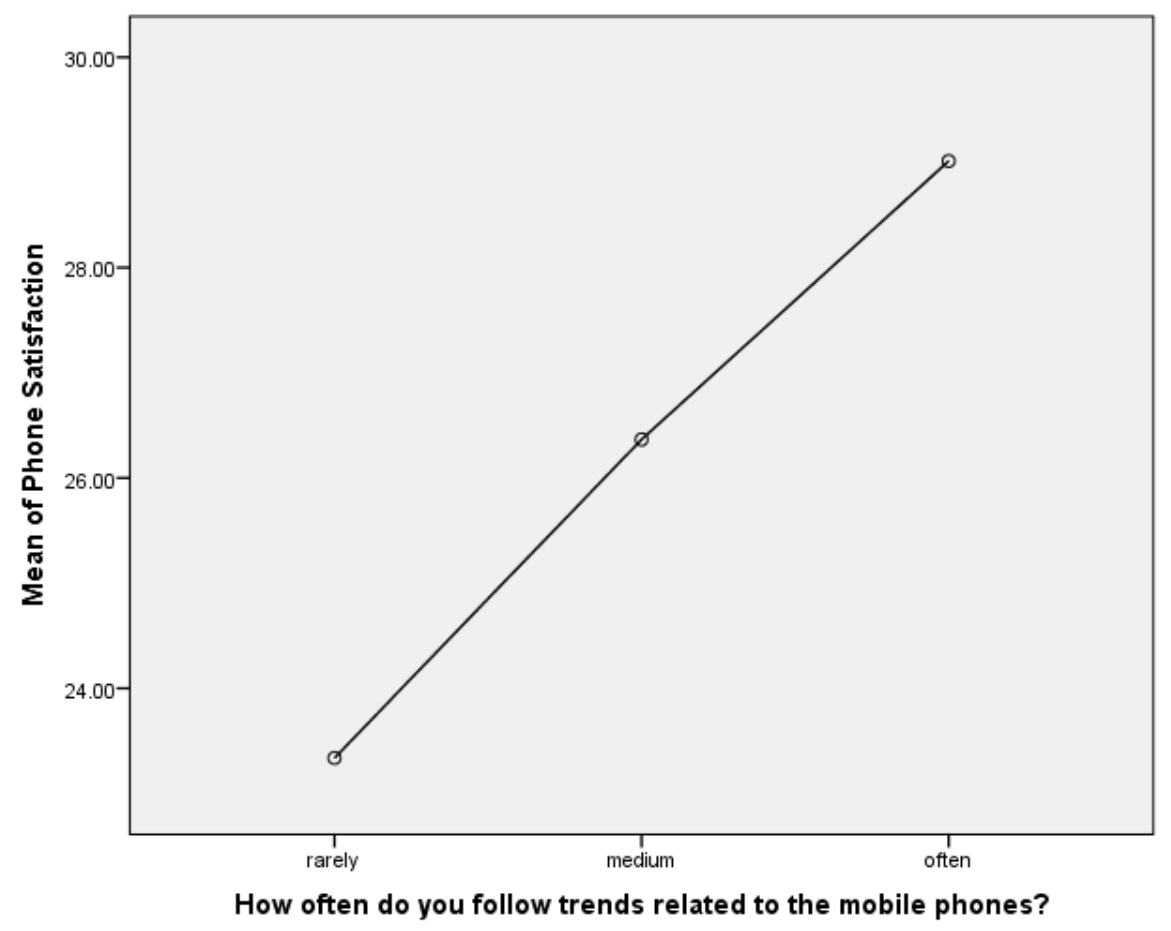

Figure 4: Differences in customer satisfaction among users according to following mobile trends

\section{CONCLUSION}

This paper explores aspects of customers' experience and market perception, and analyses its influence to the customer satisfaction with mobile phones. Introducing hypothesis H1.1.1 gives the overall picture of the customer satisfaction with mobile phones, presenting the current issue on the mobile market. Research results strongly endorse the general hypothesis and the main idea of our paper.

Regarding the influence of customer experience on their satisfaction with mobile phones, each of our individual hypotheses upholds this assumption. Research hypothesis H1.2.1 have proven that the customers that more frequently use their mobile phones are more satisfies by it. This can be indirectly connected to customer experience. It is obvious that customers who frequently use their phones would choose them more carefully, meaning that they would thoroughly inquire all aspects of market offer and carefully consider their needs. This exactly makes the customer experience. Furthermore, this is directly connected with hypotheses H1.2.2 and H1.2.3. They precisely measure the differences in customer satisfaction, according their familiarity with current models of mobile phones and mobile trends.

In conclusion, we can say that customer experience builds their loyalty, which will have the positive impact on their satisfaction with mobile phones. Therefore, the key point in managing customer satisfaction is to discover satisfaction determinants from the user's perspective and then to assess the company's performance. Mobile phone companies must strive to improve product quality so that they 
can improve customers' experiences with mobile phones.

\section{REFERENCES}

Bayraktar, E., Tatoglu, E., Turkyilmaz, A., Delen, D., \& Zaim, S. (2012). Measuring the Efficiency of Customer Satisfaction and Loyalty for Mobile Phone. Expert Systems with Applications, 39(1), 99-106.

Bong-Won, P., \& Kun Chang, L. (2011). A Pilot Study to Analyze the Effects of User Experience and Device Characteristics on the Customer Satisfaction of Smartphone Users. In K. Tai-hoon, A. Hojjat, R. J. Rosslin \& B. Maricel (Eds.), Ubiquitous Computing and Multimedia Applications (pp. 421-427): Springer Berlin Heidelberg.

Cohen, J. (1988). Statistical Power Analysis for the Behavioral Sciences (2nd ed.). Hillsdale, NJ: Lawrence Earlbaum Associates.

Cronbach, L. J. (1951). Coefficient Alpha and the Internal Structure of the Tests. Psychometrics, 16(3), 297334.

Deng, Z., Lu, Y., Kee Wei, K., \& Zhang, J. (2010). Understanding Customer Satisfaction and Loyalty: An Empirical Study of Mobile Instant Messages in China. International Journal of Information Management, 30(4), 289-300. doi: 10.1016/j.ijinfomgt.2009.10.001

Fornell, C. (1992). A National Customer Satisfaction Barometer: The Swedish Experience. Journal of Marketing, 56(1), 6-21.

Fornell, C., Johnson, M. D., Anderson, E. W., Cha, J., \& Everitt, B. (1996). The American Customer Satisfaction Index: Nature, Purpose and Findings. Journal of Marketing 60(4), 7-18.

Fournier, S., \& Mick, D. G. (1999). Redescovering Satisfaction. Journal of Marketing, 63(4), 5-23.

George, D., \& Mallery, P. (2003). SPSS for Windows Step by Step: A Simple Guide and Reference. 11.0 Update (4th ed.). Boston, USA: Allyn \& Bacon.
Hawkins, D. I., Best, R. J., \& Coney, K. A. (2004). Consumer Behavior: Building Marketing Strategy (9th ed.). NY: McGraw-Hill/Irwin.

Lee, J. Y., Kim, W. H., \& Kim, C. R. (2011). Measuring Service Quality and Customer Satisfaction in Online Trading Services on Smart Phones 2011 IEEE 3rd International Conference on Communication Software and Networks (ICCSN) (pp. 485 - 489). Xi'an: IEEE.

Lee, Y.C. (2011). m-Brand Loyalty and Post-adoption Variations for the Mobile Data Services: Gender Differences. Computers in Human Behavior, 27(6), 2364-2371. doi: 10.1016/j.chb.2011.07.015

Lilliefors, H. (1967). On the Kolmogorov-Smirnov Test for Normality with Mean and Variance Unknown. Journal of the American Statistical Association, 62, 399-402.

Milutinovic, M., Barac, D., Despotovic Zrakic, M., Markovic, A., \& Radenkovic, B. (2011). Developing Mobile Application for Learning Japanese Language - FONJAPGO. Management, 16(60), 27-34.

Oliver, R. L. (1981). Measurement and Evaluation of Satisfaction Processes in Retail Settings. Journal of Retailing, 57(3), 25-48.

Schiffman, L. G., \& Kanuk, L. L. (2004). Consumer Behavior (8th ed.). NJ: Pearson Education, Inc.

Seongwon, P., Kwangeak, K., \& Bong Gyou, L. (2011). Developing English Learning Contents for Mobile Smart Devices. In P.J. James, Y.T. Laurence \& L. Changhoon (Eds.), Future Information Technology (pp. 264-271): Springer Berlin Heidelberg.

Solomon, M. R. (2004). Consumer Behavior: Buying, Having and Being (6th ed.). NJ: Pearson Education, Inc.

Verkasalo, H. (2010). Analysis of Smartphone User Behavior 2010 Ninth International Conference on Mobile Business and 2010 Ninth Global Mobility Roundtable (ICMB-GMR) (pp. 258 - 263). Athens: IEEE. 